\title{
ABC Analysis For Inventory Management: Bridging The Gap Between Research And Classroom
}

Handanhal V. Ravinder, Montclair State University, USA Ram B. Misra, Montclair State University, USA

\begin{abstract}
${ }^{1}$
ABC analysis is a well-established categorization technique based on the Pareto Principle for determining which items should get priority in the management of a company's inventory. In discussing this topic, today's operations management and supply chain textbooks focus on dollar volume as the sole criterion for performing the categorization. The authors argue that today's businesses and supply chains operate in a world where the ability to deliver the right products rapidly to very specific markets is key to survival. With suppliers, intermediaries, and customers all over the globe, and product lives decreasing rapidly, this focus on a single criterion is misplaced. The large body of research was summarized based on multiple criteria ABC analysis that has accumulated since the 1980 s and recommend that textbooks incorporate their key findings and methods into their discussions of this topic. Suggestions are offered on how this discussion might be structured.
\end{abstract}

Keywords: Inventory; Categorization; Multicriteria; ABC Analysis

\section{INTRODUCTION}

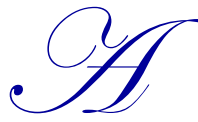

$\mathrm{BC}$ analysis is a technique for prioritizing the management of inventory. Inventories are categorized into three classes - A, B, and C. Most management efforts and oversights are expended on managing A items. $\mathrm{C}$ items get the least attention and $\mathrm{B}$ items are in-between.

Modern businesses may carry inventories of a large variety of items - finished goods, spare parts, and raw materials. Sometimes the numbers will run into the thousands. Managing these inventories involves answering, at a minimum, two questions - how much to order and when to order. Answers to these questions have to be based on an analysis of demand and lead time. Doing this one at a time for every item is neither efficient nor cost-effective, yet inventories have to be managed. They are often the biggest manageable costs of production and represent significant portions of a company's assets.

Traditionally, ABC analysis has been based on the criterion of dollar volume and on the principle that there are a relatively small number of items - category A - that account for the bulk of the dollar volume. At the other extreme, a large number of items - category $\mathrm{C}$ - account for a small share of the dollar volume. Category B items are between categories $\mathrm{A}$ and $\mathrm{C}$, both in number and dollar volume. By this criterion, $\mathrm{A}$ items are those of both high-value and high-demand and $\mathrm{C}$ items are low-value and low-demand.

However, over the last 30 years, there has been an accumulation of research questioning this focus on a single criterion - the dollar volume. It has been pointed out that other criteria can be important; among these are lead time, item criticality, durability, scarcity, reparability, stockability, commonality, substitutability, the number of suppliers, mode and cost of transportation, the likelihood of obsolescence or spoilage, and batch quantities imposed by

\footnotetext{
${ }^{1}$ This manuscript was original published in the American Journal of Business Education 7(3). Due to high download rates this manuscript has been reprinted.
} 
suppliers. Several methods have been developed to perform multi-criteria $\mathrm{ABC}$ analysis that can be quite easily implemented today.

However, operations management textbooks still focus on the single criterion of dollar-volume. In this paper, it is argued that it is time to bring multi-criteria $\mathrm{ABC}$ analysis center-stage in the textbooks. Today's businesses and supply chains operate in a world where the ability to deliver the right products rapidly to very specific markets is key to survival. With suppliers, intermediaries, and customers all over the globe, and product lives decreasing rapidly, all the criteria listed above become much more important in deciding how inventory will be classified and how it will be managed.

\section{BC ANALYSIS IN TODAY'S BUSINESS TEXTBOOKS}

In order to understand and document how $\mathrm{ABC}$ analysis is discussed in today's business textbooks, eight popular textbooks in the areas of operations and supply chain management were reviewed. The textbooks reviewed, as well as the detailed findings, are presented in Table 1. Most textbooks discuss ABC analysis prior to the discussion of inventory models and systems. The discussion begins with a mention of the Pareto Principle - the important few versus the trivial many. Annual dollar volume is the sole criterion used for the purposes of categorization. An example usually demonstrates the categorization process. Once the categorization is done, there is a brief discussion of how the different categories should be managed. Four of the eight books briefly mention the possibility of more criteria being used. This is the extent of the discussion of multiple criteria. 
Table 1. Coverage of ABC Analysis in Leading Operations \& Supply Chain Management Textbooks

\begin{tabular}{|c|c|c|c|c|c|c|c|c|c|c|c|c|}
\hline \multirow[b]{2}{*}{ \# } & \multirow[b]{2}{*}{ Author } & \multirow[b]{2}{*}{ Title } & \multirow[b]{2}{*}{ Edition } & \multirow[b]{2}{*}{ Publisher } & \multicolumn{4}{|c|}{ Traditional ABC Analysis } & \multicolumn{4}{|c|}{$\begin{array}{c}\text { Multicriteria ABC Analysis } \\
\end{array}$} \\
\hline & & & & & Discussion & Discussion & Example & $\begin{array}{c}\text { Exercises/ } \\
\text { Cases }\end{array}$ & $\begin{array}{l}\text { Post ABC } \\
\text { Discussion }\end{array}$ & Example & $\begin{array}{c}\text { Exercises/ } \\
\text { Cases }\end{array}$ & $\begin{array}{c}\text { Post ABC } \\
\text { Discussion }\end{array}$ \\
\hline 1 & $\begin{array}{l}\text { Krajewski, } \\
\text { Ritzman \& } \\
\text { Malhotra }\end{array}$ & $\begin{array}{l}\text { Operations } \\
\text { Management, } \\
\text { Processes and } \\
\text { Supply Chains }\end{array}$ & 10 & Pearson & Yes & No & No & No & No & Yes & Yes & No \\
\hline 2 & $\begin{array}{l}\text { Haizer \& } \\
\text { Render }\end{array}$ & $\begin{array}{l}\text { Operations } \\
\text { Management }\end{array}$ & 11 & Pearson & Yes & Mention & No & No & No & Yes & Yes & Brief \\
\hline 3 & Stevenson & $\begin{array}{l}\text { Operations } \\
\text { Management }\end{array}$ & 12 & $\begin{array}{l}\text { McGraw- } \\
\text { Hill }\end{array}$ & Yes & Mention & No & No & No & Yes & Yes & Brief \\
\hline 4 & Jacobs \& Chase & $\begin{array}{l}\text { Operations and } \\
\text { Supply Chain } \\
\text { Management- } \\
\text { The Core }\end{array}$ & 14 & $\begin{array}{l}\text { McGraw- } \\
\text { Hill }\end{array}$ & Yes* & Mention & No & No & No & Yes & Yes & Brief \\
\hline 5 & $\begin{array}{l}\text { Schroeder, } \\
\text { Goldstein \& } \\
\text { Rungtusanatham }\end{array}$ & $\begin{array}{l}\text { Operations } \\
\text { Management in } \\
\text { the Supply Chain } \\
\text { - Decisions \& } \\
\text { Cases }\end{array}$ & 6 & $\begin{array}{l}\text { McGraw- } \\
\text { Hill }\end{array}$ & Yes* & No & No & No & No & Yes & Yes & Brief \\
\hline 6 & $\begin{array}{l}\text { Swink, Melnyk, } \\
\text { Bixby Cooper \& } \\
\text { Hartley }\end{array}$ & $\begin{array}{l}\text { Managing } \\
\text { Operations - } \\
\text { Across The } \\
\text { Supply Chain }\end{array}$ & 2 & $\begin{array}{l}\text { McGraw- } \\
\text { Hill }\end{array}$ & Yes* & No & No & No & No & Yes & Yes & Brief \\
\hline 7 & $\begin{array}{l}\text { Russell \& } \\
\text { Taylor }\end{array}$ & $\begin{array}{l}\text { Operations } \\
\text { Management- } \\
\text { Creating Value } \\
\text { Along The Supply } \\
\text { Chain }\end{array}$ & 7 & Wiley & Yes & Mention & No & No & No & Yes & Yes & Brief \\
\hline 8 & Reid \& Sanders & $\begin{array}{l}\text { Operations } \\
\text { Management }\end{array}$ & 5 & Wiley & Yes & No & No & No & No & Yes & Yes & Adequate \\
\hline
\end{tabular}

*After discussion of inventory models and systems. 


\section{STATUS OF RESEARCH ON MULTI-CRITERIA ABC ANALYSIS}

Since Flores and Whybark (1987) first proposed looking at more than one criterion, this has been an area of active research. There has been broad agreement that $\mathrm{ABC}$ analysis should consider more than one criterion. The methodology involves three main steps once the relevant criteria have been identified. The first is to determine what weights to assign to the different criteria and the second is to score each item on each criterion. If the criteria are measured on a variety of scales, this second step might involve rescaling the scores onto a $0-1$ or $0-100$ scale. The final step is to combine weights and scores to produce the weighted score. Over the years, three broad approaches have emerged to perform the weighting. It has been assumed that the different criteria permit unambiguous scoring of the items and that this is not an issue.

\subsection{Subjective Weighting and Rating}

This approach scores each type of inventory item on each criterion and then combines the different scores using a subjective weighting scheme. Many researchers have used the framework provided by the Analytic Hierarchy Process (AHP) to accomplish this (Flores, Olsen, \& Dorai, 1992; Partovi \& Burton, 1993; Partovi \& Hopton, 1994; Gajpal, Ganesh, \& Rajendran, 1994; Kabir, Hasin, \& Khondokar, 2011; Braglia, Grassi, \& Montanari, 2004). AHP relies on pairwise comparisons of criteria with respect to an overall objective to derive the weights to place on the criteria. Alternatives too can be compared pairwise with respect to each criterion. In this case, the alternatives are the various inventory items. Pairwise comparison of thousands of items with respect to each criterion is clearly a hopeless task. Instead, the alternatives are scored along each criterion and the weights are applied to these scores. This is AHP in its ratings mode. The result is a weighted score that can be used to rank the items prior to assigning them into different categories. The pairwise comparisons needed to determine the weights are performed by managers who are knowledgeable about the inventory items and the tradeoffs among the different criteria. This is a one-time task as long as the criteria or management preferences among them don't change.

AHP has been used in a variety of business decision-making settings and decision-makers have found it intuitive and easy to use (Saaty, 1995; Zahedi, 1986; Vargas, 1990). Its theoretical underpinnings are strong and it has been incorporated into software (Expert Choice) that makes the process easy to implement.

While researchers have not proposed this in the context of $\mathrm{ABC}$ analysis, there are other ways of implementing rating and weighting schemes. For example, Multi-Attribute Utility Theory provides theory and methodology for assessing weights, scoring alternatives, and combining weights and scores to arrive at a final score (or utility) for an alternative. The most robust and easy to use model is an additive model that is very similar to the AHP in its ratings mode. See, for example, SMART (Edwards \& Barron, 1994). Software also exists that can implement this process easily.

Whichever method is used, once the weights are obtained, the weighting and scoring can be easily performed on a spreadsheet.

\subsection{Linear Optimization}

Other researchers (Ramanathan, 2004; Ng, 2005; Zhou \& Fan, 2007; Hadi-Vencheh, 2010) have used a linear optimization approach to determining the weights. Their view is that the subjective inputs needed in the weighting and rating approach are cumbersome to obtain and undesirable because of possible inconsistencies. Instead, they would rather let the data itself suggest weights that minimize some reasonable criterion.

Ramanathan (2004) solves a linear programming problem for each item in inventory to determine weights that maximize the weighted score for that item subject to constraints that the weighted sum for every item using this same set of weights is less than or equal to one. Thus, one immediate criticism of this model is that with more than a handful of items, the process will become cumbersome and time-consuming.

$\mathrm{Ng}$ (2005) addresses this issue by proposing a DEA-type model similar to Ramanathan's, but which is then transformed into another set of problems, the structure of which makes it easy to recognize the optimal solution 
without the use of a linear optimizer. Input is required from the business decision-maker in the form of a ranking of the weights associated with the criteria for each item, but this ranking is not critical to the mechanics of the method which can be implemented on a spreadsheet. At the end of the process, each item in inventory is given a score which can then be used to perform the ABC analysis. Hadi-Vencheh (2010) proposes a nonlinear extension to the $\mathrm{Ng}$ model.

A second criticism of Ramanathan's model is that the method can provide high scores to items that score highly on an unimportant criterion. Zhou \& Fan (2007) propose a refinement which avoids this problem.

\subsection{Clustering, Genetic Algorithms, and Neural Networks}

A third approach to categorization for the purpose of $\mathrm{ABC}$ analysis relies on the methods of artificial intelligence and data-mining. All these methods start with a training set - a set of inventory items that have already been classified on the basis of multiple criteria as $\mathrm{A}, \mathrm{B}$, or $\mathrm{C}$, by managers who are familiar with them - to learn the appropriate transformations necessary to combine criteria values and determine cut-offs.

Guvenir and Erel (1998) propose an approach called GAMIC which starts with the framework of AHP to deal with multi-criteria $\mathrm{ABC}$ analysis. GAMIC uses genetic algorithms to learn from the training set the weights to be assigned to each criterion and, further, to determine the cut-offs between the three categories. Unknown weights and cutoffs are encoded as chromosome vectors that result in a particular classification. Given this encoding scheme, the method applies standard genetic operators (reproduction, crossover, and mutation) to create new generations of solutions. Each chromosome (solution) is tested using a fitness function and the best solutions become members of the next generation. This process continues iteratively until the algorithm converges on the training set; i.e., provides weights and cut-offs that reproduce (for the training set) the decision-maker's categorizations. These weights and cut-offs can then be used for other inventory categorization tasks. In their comparisons, their algorithm performed better than AHP - in the sense of having fewer misclassifications when compared with the decision-maker's classifications of the items. One limitation of this approach is that criteria can only be quantitative.

Partovi and Anandarajan (2001) follow a similar process but using artificial neural networks (ANN) to solve an inventory classification problem with four criteria - unit price, ordering cost, demand range, and lead time. The inputs to the network are values of these criteria for different inventory items. The output of the network is a categorization of a set of criteria values as A, or B, or C. Thus, their network consists of four input neurons (one for each input criterion), 16 hidden neurons, and three output neurons (one for each inventory category). Two kinds of learning algorithms are used - back propagation and genetic algorithms. Once the network was trained, it was used on hold out data as well as an "out of population" sample. Results (\% misclassification compared with decisionmaker categorization) were encouraging and point to ANN being a viable way of performing multi-criteria $\mathrm{ABC}$ analysis.

Gulsen and Ozkan (2013) treat ABC analysis as a clustering problem in which the inventory items that have to be categorized are partitioned into three "fuzzy" clusters by minimizing some appropriate clustering function. Fuzzy clustering is the appropriate technique to use given that it is possible for some inventory items to belong to more than one cluster. The center of a cluster is described by an $\mathrm{n}$-dimensional vector, where $\mathrm{n}$ is the number of criteria to be used for the $\mathrm{ABC}$ analysis. Each inventory item is similarly an n-dimensional vector. Membership of the clusters is indicated by a membership value that is between 0 and 1 . The objective to be minimized is the distance between the current centers of each cluster and each inventory item weighted by the membership value modified by a "fuzzifier." The algorithm starts with initial values for the cluster centers, followed by calculating a membership value for each inventory item. This allows recalculation of the cluster centers. If the new cluster centers are within some $\varepsilon$ of the current cluster centers, the algorithm stops; otherwise, the next iteration begins with the new cluster centers. Once the stopping rule has been met, the output of the algorithm is the membership value for each item for each cluster. An item is assigned to a cluster based upon the highest of its membership values. Thus, at the end of the process, three (for three categories) clusters will have been identified. The next step is to label the clusters appropriately. Labeling is done on the basis of the average criterion value within a cluster. This is calculated by adding all the criterion values for all items within a cluster and dividing by the number of items in the cluster. The 
cluster with the highest average criterion value is labeled $\mathrm{A}$, the next highest as $\mathrm{B}$, and the last one as $\mathrm{C}$. In actual application of the method, it is suggested that item scores on each criterion be rescaled to a $0-1$ scale using a simple linear transform.

In concept, each of the above three approaches will produce an $\mathrm{ABC}$ categorization with high reliability; in other words, there is a high degree of overlap with the categorizations of human decision-makers.

\subsection{Other Approaches}

Other approaches have been proposed to the ABC categorization problem. Rough set theory (Pawlak, 1991) has been used by Gomes and Ferreira (1995) and Chen, Li, Levy, Hipel, and Kilgour (2008) to perform the ABC categorization with the use of training sets. Bhattacharya, Sarkar, and Mukherjee (2007) present a distance-based consensus method using the concepts of ideal and negative ideal solutions from the TOPSIS (Technique for Order Preference by Similarity to Ideal Solution) approach to ranking. They demonstrate the practicality of their approach by applying it to the inventory items of a pharmaceutical company. Liu \& Huang (2006) and Torabi, Hatefi, \& Pay (2012) present modified versions of a DEA model to take both quantitative and qualitative criteria into account in $\mathrm{ABC}$ analysis.

\section{DISCUSSION}

This considerable body of research shows that there are many feasible ways of implementing multi-criteria $\mathrm{ABC}$ analysis in practical situations - some extremely simple, while others quite sophisticated. Businesses have their choice of what to pick based on their needs and capabilities.

While the optimization-based approaches and artificial intelligence-based approaches have been motivated by the desire to get away from subjective weights, the authors believe that subjectivity, in this case, is a good thing. Management priorities must be reflected in the weights and as these priorities change, the weights must change. Only management can decide on the appropriate trade-off; for example, between lead time and criticality or between the likelihood of obsolescence and batch quantities, and the categorization technique used must not take away this obligation/right from management. It might be argued that management's priorities are reflected in the categorization provided in the training set necessary for the AI-based approaches, but managers have to be able to perform such a categorization in the first place for the large numbers of items that training sets typically require. The greater the number of criteria, the larger the training set will have to be for the AI-based methods to reliably learn the combination rules. Making choices in the presence of multiple criteria is not a trivial task and needs assistance. Further, when management priorities do change, a new training set will have to be created and the AIbased algorithms run again. It is not clear whether many businesses are currently equipped to do this. In contrast, the weighting and rating methods using either AHP or some other multi-attribute choice method provide managers with a transparent way of making their priorities clear and applying them to the $A B C$ categorization. Software systems exist that make this process painless and which easily accommodate changes to priorities. Thus, in both concept and implementation, the authors believe that subjective weighting and rating is preferable to the other approaches and should be the method of choice.

In the next section, suggestions are offered on how textbooks should present a discussion of multi-criteria $\mathrm{ABC}$ analysis.

\section{DISCUSSING MULTI-CRITERIA ABC ANALYSIS IN TEXTBOOKS}

Most textbooks discuss $\mathrm{ABC}$ analysis prior to discussing the different inventory models (EOQ, EBQ, etc.) and inventory systems (continuous review, periodic review). This makes it difficult to have a meaningful discussion of how to tailor inventory management policies to the needs of the different categories. For this reason, the authors suggest that $\mathrm{ABC}$ analysis be discussed after coverage of inventory models and systems. By then, students will have had exposure to the various costs and trade-offs of inventory management and be in a much better position to appreciate the inventory categorization issue. 
It is suggested that operations management textbooks adopt the following structure for the discussion of $\mathrm{ABC}$ analysis.

- Introduction to $\mathrm{ABC}$ analysis and the rationale for it: the Pareto principle and the need to separate the important few from the trivial many.

- Criteria for ABC analysis: Motivate the need for multiple criteria - today's extended supply chains with emphasis on rapid change, quick response, low cost, and high reliability. Discuss and define criteria like annual volume, usage rates, demand patterns, unit price, lead time, criticality, serviceability, durability, number of suppliers, scarcity of items, replenishment cost, substitutability, etc. However, not all of these will be relevant in every inventory management situation.

- The ABC categorization: Items will, generally speaking, be classified on the basis of multiple criteria, as shown below. In reality, one would expect high price to reflect high criticality, scarcity, low substitutability, and low number of suppliers. However, this need not always be the case; but where such associations exist, they would simplify the categorization.

A. High: Demand, Price, Obsolescence, Spoilage, Criticality, Scarcity, Replenishment Cost, Lead time, Variability (of Demand, Price, Lead time, etc.)

Low: Serviceability, Number of Suppliers, Substitutability

B. Moderate: Demand, Price, Criticality, Scarcity, Replenishment Cost, Lead time, Variability (of Demand, Price, Lead time, etc.), Serviceability, Number of Suppliers, Substitutability

C. High: Serviceability, Number of Suppliers, Substitutability Low: Demand, Price Obsolescence, Spoilage, Criticality, Scarcity, Replenishment Cost, Leadtime, Variability (of Demand, Price, Lead time, etc.)

- The $\mathrm{ABC}$ methodology: For undergraduate students, it is recommended that the weighting and rating method be discussed in its simplest form, where weights are assigned directly by management on the basis of the importance of criteria. The model here should be the factor rating system used for facility location. Sophisticated methods for assessing criteria weights, like AHP or multi-attribute utility, might be saved for discussion with graduate students.

- A worked example, including at least one qualitative criterion: An end-of-chapter case study might provide a more realistic exercise, perhaps involving the use of AHP software if the textbook provides access.

- A detailed discussion of the management of A, B, and C items. What policies should one use for different categories? Current textbooks rarely follow up the $\mathrm{ABC}$ categorization with an adequate discussion of how $\mathrm{A}, \mathrm{B}$, and $\mathrm{C}$ inventory items might be managed.

\section{CONCLUSION}

Traditionally, ABC analysis has been used to classify various inventory items into three categories - A, B, and C. This has been done based on the criterion of dollar volume. In the current globalized hyper-responsive business environment, a single criterion is no longer an adequate guide to the management of inventories and multiple criteria have to be considered. Researchers in operations and inventory management recognized this fact in the early 1980s and since then have proposed numerous approaches to multi-criteria $\mathrm{ABC}$ classification. However, textbooks of operations management and supply chain management have not followed their lead but continue to discuss ABC analysis based on the idea of annual dollar volume. In this paper, the authors review the literature to-date and argue that multi-criteria $\mathrm{ABC}$ analysis is a mature concept that needs to make its way into textbooks. Authors should revise their coverage to include a detailed coverage of the concept and methodology of multi-criteria $\mathrm{ABC}$ analysis. Such a revision will make their textbooks more relevant to the current business environment and provide students with the skills they need to function and contribute in the workplace. As a result, companies will be able to manage their inventories better and be more competitive in the marketplace. 


\section{AUTHOR INFORMATION}

Handanhal Ravinder has been an associate professor in the Information and Operations Management department in the School of Business at Montclair State University since Fall 2012. Prior to that, he spent 12 years in the healthcare industry in various market research and business analytics positions. Dr. Ravinder received his Ph.D. from the University of Texas at Austin and taught for many years at the University of New Mexico. His research interests are in operations management, healthcare supply chain, and decision analysis. He has published in Management Science, Decision Analysis, and American Journal of Business Education, among others. E-mail: ravinderh@mail.montclair.edu (Corresponding author)

Ram Misra is a full professor in the Information and Operations Management department in the School of Business at Montclair State University. Prior to joining the Business School faculty, Dr. Misra was an executive director at Telcordia Technologies, heading the service assurance division. His academic research has focused on productivity and outsourcing, IT investment and open source processes and initiatives and has been published in Decision Sciences Journal of Innovative Education, Journal of Academy of Business and Economics, and Information Technology Journal among numerous others. Dr. Misra received a PhD degree in Industrial Engineering and Operations Research from Texas A \& M University.

\section{REFERENCES}

Altay Guvenir, H., \& Erel, E. (1998). Multi-criteria inventory classification using a genetic algorithm. European Journal of Operational Research, 105(1), 29-37.

Bhattacharya, A., Sarkar, B., \& Mukherjee, S. K. (2007). Distance-based consensus method for ABC analysis. International Journal of Production Research, 45(15), 3405-3420.

Braglia, M., Grassy, A., \& Montana, R. (2004). Multi-attribute classification method for spare parts inventory management. Journal of Quality in Maintenance Engineering, 10(1), 55-65.

Chen, Y., Li, K. W., Levy, J., Hype, K. W., \& Kilgore, D. M. (2008). A rough set approach to multiple criteria ABC analysis. In Transactions on rough sets VIII (pp. 35-52). Springer Berlin Heidelberg.

Edwards, W., \& Barron, F. H. (1994). SMARTS and SMARTER: Improved simple methods for multi-attribute utility measurement. Organizational Behavior and Human Decision Processes, 60(3), 306-325.

Gomes, L. F. A. M., \& Ferreira, A. C. S. (1995). The multi-criteria ABC analysis - An application of rough set theory. Foundations of Computing and Decision Sciences, 20(3).

Flores, B. E., \& Whybark, D. C. (1987). Implementing multiple criteria ABC analysis. Journal of Operations Management, 7(1), 79-85.

Flores, B. E., Olson, D. L., \& Dorai, V. K. (1992). Management of multi-criteria inventory classification. Mathematical and Computer Modelling, 16(12), 71-82.

Gopal, P. P., Ganesh, L. S., \& Rajendran, C. (1994). Criticality analysis of spare parts using the analytic hierarchy process. International Journal of Production Economics, 35(1), 293-297.

Hadi-Vencheh, A. (2010). An improvement to multiple criteria ABC inventory classification. European Journal of Operational Research, 201(3), 962-965.

Kabir, G., Hasin, M. A. A., \& Khondokar, M. A. H. (2011). Fuzzy analytical hierarchical process for multi-criteria inventory classification. Proceedings of the International Conference on Mechanical Engineering, 18-20 December, Dhaka, Bangladesh.

Liu, Q., \& Huang, D. (2006). Classifying ABC inventory with multi-criteria using a data envelopment analysis approach. In Intelligent systems design and applications, 2006. ISDA'06. Sixth International Conference on IEEE (Vol. 1, pp. 11851190).

Ng, W. L. (2007). A simple classifier for multiple criteria ABC analysis. European Journal of Operational Research, 177(1), 344-353.

Partovi, F. Y., \& Anandarajan, M. (2002). Classifying inventory using an artificial neural network approach. Computers \& Industrial Engineering, 41(4), 389-404.

Partovi, F. Y., \& Burton, J. (1993). Using the analytic hierarchy process for ABC analysis. International Journal of Operations \& Production Management, 13(9), 29-44.

Pawlak, Z. (1991). Rough sets: Theoretical aspects of reasoning about data. Dordrecht: Kluwer Academic Publishing. ISBN 07923-1472-7.

Ramanathan, R. (2006). ABC inventory classification with multiple-criteria using weighted linear optimization. Computers \& Operations Research, 33(3), 695-700. 
Ravinder, H.V. \& Misra, R.B. (2014). ABC analysis for inventory management: bridging the gap between research and classroom. American Journal of Business Education, 7, 257-264.

Saaty, T. L. (1995). Transport planning with multiple criteria: The analytic hierarchy process applications and progress review. Journal of advanced transportation, 29(I), 81-126.

Vargas, L. G. (1990). An overview of the analytic hierarchy process and its applications. European Journal of Operational Research, North-Holland.

Yu, M. C. (2011). Multi-criteria ABC analysis using artificial-intelligence-based classification techniques. Expert Systems with Applications, 38(4), 3416-3421.

Zahedi, F. (1986). The analytic hierarchy process-a survey of the method and its applications. Interfaces, 16(4).

Zhou, P., \& Fan, L. (2007). A note on multi-criteria ABC inventory classification using weighted linear optimization. European Journal of Operational Research, 182(3), 1488-1491. 


\section{NOTES}

